\title{
Topographical control of prostate cancer cell migration
}

\author{
MICHAL SARNA $^{1,3^{*}}$, EWA WYBIERALSKA $^{1 *}$, KATARZYNA MIEKUS ${ }^{1,2}$, \\ JUSTYNA DRUKALA $^{1}$ and ZBIGNIEW MADEJA ${ }^{1}$
${ }^{1}$ Department of Cell Biology, Faculty of Biochemistry, Biophysics and Biotechnology, Jagiellonian University, 30387 Cracow;
${ }^{2}$ Department of Transplantation, Polish-American Institute of Pediatrics, Jagiellonian University, 30-663 Cracow;
${ }^{3}$ Department of Medical Physics and Biophysics, Faculty of Physics and Applied Computer Science, AGH University of Science and Technology, 30-059 Cracow, Poland

Received April 2, 2009; Accepted June 17, 2009

DOI: 10.3892/mmr_00000185

\begin{abstract}
Tumour cells can efficiently respond to numerous factors affecting their motility. However, the role of substrata topography in the regulation of cancer cell motility has been quantitatively studied in only a few cases. We demonstrated that human (DU-145) and rat (MAT-LyLu and AT-2) prostate cancer cells are efficiently contact guided by underlying normal cells when invading surrounding tissues and forming metastases. Prostate cancer cells moving on the surface of fibroblasts displayed significantly greater cell displacement than those moving on plastic substrata. This effect was correlated with the polarization (contact guidance) and increased speed of cell movements. We subsequently verified the hypothesis that the observed contact guidance of prostate cancer cells migrating on the surface of fibroblasts results from their reaction to the microtopography of normal cells. The responses of cells to multiple grooved substrata of a size corresponding to the dimensions of a compact monolayer culture of human skin fibroblasts were studied, and the migration of prostate cancer cells appeared to be efficiently affected by topographical features of the substratum. In contrast to random movement under control conditions, all investigated prostate cancer cell lines grown on patterned substrata migrated mainly along artificial grooves and covered, as a result of contact guidance, a longer distance than cells on plain substrata. Moreover, the reaction to microtopography was correlated with the metastatic activity of prostate cancer cells. In conclusion, our results show that grooved substrata have a substantial effect on prostate cancer migration. Since all types of tissue show some kind of
\end{abstract}

Correspondence to: Dr Zbigniew Madeja, Department of Cell Biology, Faculty of Biochemistry, Biophysics and Biotechnology, Jagiellonian University, Gronostajowa 7, 30-387 Cracow, Poland

E-mail: z.madeja@uj.edu.pl

*Contributed equally

Key words: contact guidance, cell migration, contact stimulation, prostate cancer, invasion patterning and alignment, topographic factors may be crucial for the effective migration of prostate cancer cells during the metastatic process.

\section{Introduction}

Cell migration is a critical step in tumour invasion, and several reports have demonstrated a correlation between the motility of tumour cells and their metastatic potential $(1,2)$. The migration of tumour cells is controlled by numerous factors, including chemoattractants, chemorepellents, extracellular matrix components and electric fields (3-6). The motile activity of tumour cells is also affected by contact with neighbouring cells. Contrary to normal cells, which usually exhibit a decrease in motile activity upon collision with other cells as a result of the 'contact inhibition' of cell movement (7-9), cancer cells usually exhibit a deficiency in contact inhibition $(10,8)$. Moreover, increasing evidence suggests that some tumour cells may actually experience an increase in motile activity as a result of direct physical contact with normal cells $(8,9,11-14)$. Abercrombie (8) suggested that tumour cells may be guided by underlying normal cells when invading surrounding tissues and forming metastases. In previous reports, we demonstrated by means of quantitative studies that some tumour cells (including rat prostate cancer cells), when cultured on the surface of aligned fibroblasts, showed contact guidance by migrating along the long axes of fibroblasts, leading to more effective cancer cell displacement than in the case of no contact with normal cells $(12,15,16)$. The mechanism of this reaction is at present unclear. It was suggested that the movement of tumour cells could be guided by oriented fibronectin molecules covering fibroblasts $(12,15)$. Indeed, the orientation of tumour cells by aligned macromolecules has been observed in several earlier studies $(17,18)$. However, another possibility involves the efficient migration of cancer cells moving on the surface of normal fibroblasts as a result of their reaction to the micrometric topography of the substratum; i.e., the shape and orientation of normal cells.

A wide variety of normal cells, including fibroblasts, neurons, leukocytes, macrophages, chondrocytes, endothelia and epithelia, respond to microtopography during a reaction 
often termed 'contact guidance' (reviewed in ref. 19). These effects were demonstrated owing to advances in the microfabrication of accurate micro-scale substrates for the study of cell migration. Although research concerning contact guidance on artificial groove/ridge structures has been carried out with various non-malignant cells, there are only a few corresponding quantitative studies concerning tumour cells (20-24). In most of these studies, under in vitro conditions, tumour cells were observed to be much less sensitive to contact guidance by the topography of the supporting artificial surfaces than normal cells (20-22). However, in these reports, the movement of cancer cells on topography was not studied, and the contact guidance of cells was estimated by the orientation and morphology of the investigated cells. The effect of surface topography on the migration of neoplastic cells was demonstrated by Mello et al (23). The results of this study indicate that the effect of surface topography on the directional migration of $\mathrm{T}$ lymphoma cells was very weak.

In a previous study (25), we showed that murine P388D1 macrophages experience increases in the speed and persistence of cell movement when moving on substrata with microfabricated grooves 0.5 and $5 \mu \mathrm{m}$ deep and $10 \mu \mathrm{m}$ wide, which is of similar size as normal fibroblasts responsible for the guidance of cancer cells $(12,15,16)$. In this study, by studying the response of prostate cancer cells to multiple grooved substrata of a size corresponding to the dimensions of normal fibroblasts, we examined whether the contact guidance of prostate cancer cells migrating on the surface of fibroblasts results from their reaction to the microtopography of normal cells.

\section{Materials and methods}

Cell culture. Experiments were carried out on two wellcharacterized rat prostate cancer cell lines with markedly different metastatic abilities (Dunning rat model): MAT-LyLu and AT-2 cells. These cells are originally derived from a spontaneously-occurring prostate tumour in an inbred Copenhagen rat and, when injected into rats, metastasize in $>90 \%$ and $<10 \%$ of cases, respectively, $(6,26)$. The DU-145 human prostate cancer cell line was also used. MAT-LyLu and AT-2 cells were cultured in Roswell Park Memorial Institute (RPMI)-1640 media (Sigma, St. Louis, MO, USA), whereas DU-145 cells were cultured in Dulbeco's Modified Eagle's Medium Nutrient Mixture F-12 HAM supplemented with $100 \mathrm{IU} / \mathrm{ml}$ penicillin and $100 \mu \mathrm{g} / \mathrm{ml}$ streptomycin (Polfa, Tarchomin, Poland) in the presence of 5\% (MAT-LyLu and AT-2 cells) or 10\% (DU-145 cells) heat-inactivated foetal calf serum (Gibco Laboratories, New York, NY, USA). All cells were cultured in a humidified atmosphere with $5 \% \mathrm{CO}_{2}$ at $37^{\circ} \mathrm{C}$.

Human skin fibroblasts isolated from healthy donors were used for experiments between the 5th to 15th passage. Cells were cultured in Eagle's Minimal Essential Medium (Sigma), supplemented with $100 \mathrm{IU} / \mathrm{ml}$ penicillin and $100 \mu \mathrm{g} / \mathrm{ml}$ streptomycin in the presence of $10 \%$ foetal calf serum with $5 \% \mathrm{CO}_{2}$ at $37^{\circ} \mathrm{C}$. The cells were plated at an initial cell density of $1 \times 10^{5}$ cells per Corning flask, and grown to confluence.

Measurement of fibroblast topography and substratum patterning. The topography of fibroblasts was determined by Atomic Force Microscopy (Park Scientific Instruments,
CP-Research Atomic Force Microscope). Measurements were performed in contact dc mode on a fixed monolayer of fibroblasts in the presence of physiological buffered saline.

A technique for preparing micro-textured polymer substrates for cell behavior studies was employed in order to produce predetermined features in polymeric material (27). The surface was modified with a hot embossing imprint lithography process (28), forming a regular microgroove pattern in the polymer substrate. In brief, this process consists of imprinting the topography of the matrices in thermoplastic material. A silicone master is pressed into the thermoplastic material by applying a specified force into a polymer substrate at elevated temperatures. The process takes place in a vacuum heater. As a matrix, we used a polydimethylsiloxane stamp. The polymer substrate was a polyethylene cover slip with a diameter of $25 \mathrm{~mm}$ (Sarstedt, Nümbrecht, Germany). The surface of this polymer was physically isotropic at the submicron level and chemically inactive even after full curing. Atomic Force Microscopy (Veeco, Multimode Atomic Force Microscope) was employed for the verification of the features of the obtained multiple grooved substrata. Measurements were performed in contact dc mode in air.

Time-lapse monitoring of the movement of individual cells. Cells were examined with a Leica DM IRE2 microscope at $37^{\circ} \mathrm{C}$. Prostate cancer cells were plated in culture dishes at a density of 80 cells $/ \mathrm{mm}^{2}$. Co-cultures of rat prostate cancer cells and human skin fibroblasts were initiated by plating the prostate cancer cells $\left(80\right.$ cells $\left./ \mathrm{mm}^{2}\right)$ onto the confluent monolayer of aligned fibroblasts. In the experiments on the effects of substratum topography on prostate cancer cell motility, the cells were plated onto grooved substrata at the same density as described above. The movement of cells was recorded for $4 \mathrm{~h}$ (MAT-LyLu and AT-2 cells) or $8 \mathrm{~h}$ (DU-145 cells) with 5-min time intervals. Cell images were recorded with a Leica DC350 FX digital camera and processed as previously described $(12,29)$. The identification of prostate cancer cells in co-cultures was unproblematic since, in contrast to the stationary normal fibroblasts, cancer cells showed apparent locomotion. Nevertheless, to aid in the discrimination of tumour cells from underlying fibroblasts, in some experiments tumour cells were fluorescently stained with 1,1'-dioctadecyl3,3,3',3'-tetramethylindocarbocyanine perchlorate (Molecular Probes, Leiden, Holland) prior to experimentation, as previously described $(12,16)$.

The tracks of individual cells were determined as previously described, from the series of changes observed in the centroid positions of the cells $(12,30)$. The trajectories of cells from no less than three independent experiments were pooled. For the analysis of cellular motility parameters, files containing the tracing data were read into the Mathematica program (Wolfram Research Inc., Champaign, IL, USA). The following parameters of cell movement were calculated: i) average speed of cell movement (total length of cell trajectory/time of recording, where the total length of cell trajectory $(\mu \mathrm{m})$ is the sum of a sequence of ' $\mathrm{n}$ ' straight-line segments, each corresponding to the cell centroid translocation in a given time interval); ii) total length of cell displacement $(\mu \mathrm{m})$ (direct distance from cell starting point to final position); iii) coefficient of movement efficiency (CME) (cell displacement/ 
A.

B.

C.

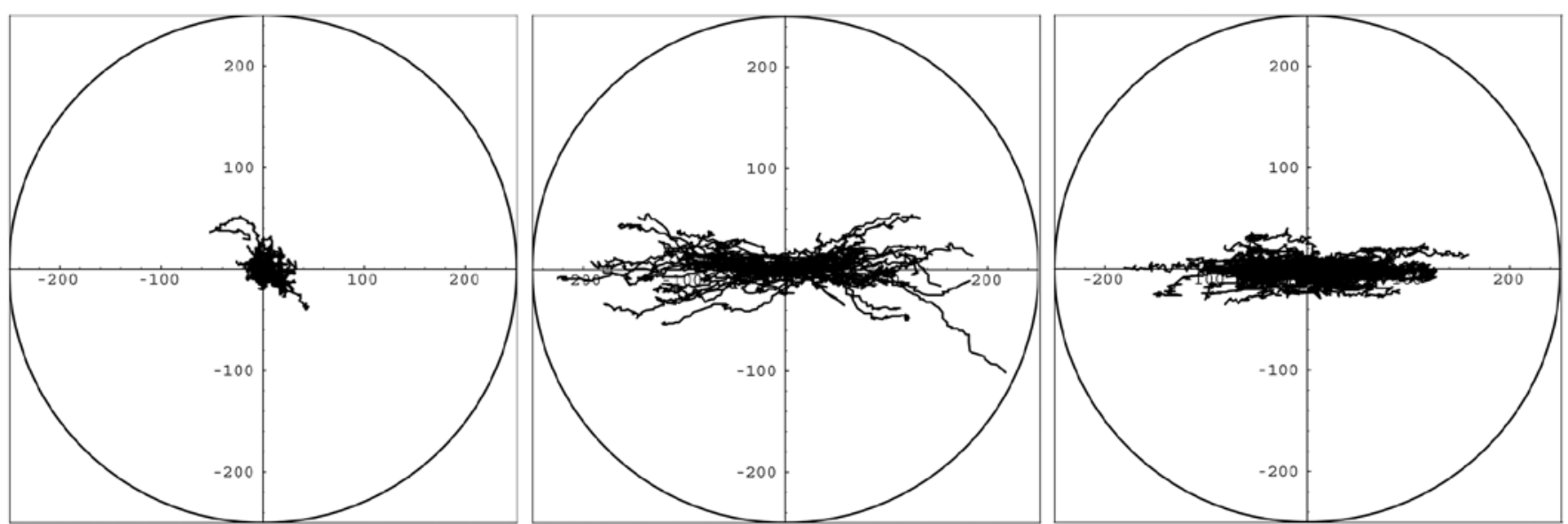

Figure 1. Composite trajectories of DU-145 cells migrating (A) on the isotropic surface of a culture dish, (B) on the surface of underlying contact-inhibited human skin fibroblasts, and (C) on patterned substrata. Trajectories are displayed in circular diagrams in which the initial point of each trajectory is placed at the origin of the plot. Each panel shows the trajectories of 100 cells. The movement of cells was recorded for $8 \mathrm{~h}$, with 5 -min time intervals.

cell trajectory length, where the $\mathrm{CME}=1$ for cells moving persistently along a single straight line in a given direction and 0 for cells with random movement; iv) average directional cosine $\left(\sum_{\mathrm{n}} \cos 2 \theta / n\right)$, where $\theta$ is defined as the directional angle between the $0 \mathrm{X}$ axis (parallel to the long axes of fibroblasts or grooves) and the vector $\mathrm{AB}$, where $\mathrm{A}$ and $\mathrm{B}$ are the first and subsequent positions of the cell, respectively (parameter $=1$ for cells moving parallel to the $0 \mathrm{X}$ axis and 0 for cells with random movement); v) $\Sigma_{\mathrm{n}} \cos 2 \theta / n$ of the final position, where $\theta$ is defined as the directional angle between the $0 \mathrm{X}$ axis (parallel to the long axes of fibroblasts or grooves) and the vector $\mathrm{AB}$, where $\mathrm{A}$ and $\mathrm{B}$ are the first and final positions of the cell, respectively (parameter $=1$ for cells moving parallel to the $0 \mathrm{X}$ axes and 0 for cells with random movement).

Data analysis. A total of 50-100 cells were analyzed for each measured value. The mean \pm standard error (SEM) of each parameter was calculated. Statistical significance was determined using the Student's t-test.

The significance of the orientation of cell locomotion against random movement was calculated using Rayleigh's distribution. The probability that cell locomotion would be random was determined according to the equation: $\mathrm{P}=\mathrm{e}^{-}\left(\mathrm{L}^{2} \mathrm{n}\right)\left(10^{-4}\right)$, where $\mathrm{L}=\left[\left(\sum_{\mathrm{n}} \sin 2 \theta\right)^{2}+\left(\sum_{\mathrm{n}} \cos 2 \theta\right)^{2}\right]^{1 / 2} / \mathrm{n}(0.01)$, and $\mathrm{n}$ is the total number of cells. A probability level of 0.001 was used as the limit for significant directional movement (12).

\section{Results}

Characterization of the migration of DU-145 human prostate cancer cells on underlying aligned fibroblasts. In previous reports, we demonstrated that several rat cancer cell types were efficiently contact guided by normal fibroblasts $(12,15,16)$. In a compact monolayer culture, human skin fibroblasts show very low motility and practically do not change position for a long time period. Moreover, confluent cultures of fibroblasts show enormous areas in which cells are orientated and aligned parallel to one another. For this reason, these fibroblasts were chosen as a model for the investigation of the contact guided motility of cancer cells in co-cultures with normal cells $(12,15)$. We first examined whether contact guidance on the surface of normal fibroblasts could also be observed in the case of human DU-145 prostate cancer cells. Analysis of time-lapse recordings revealed that DU-145 cells are efficiently contact guided by normal fibroblasts. While cancer cells migrated primarily along the long axis of the underlying fibroblasts, their trajectories were orientated along the $0 \mathrm{X}$ axis (the axis parallel to the long axes of the fibroblasts) (Fig. 1B), which is reflected by the values of the average directional cosine (Table I). On the other hand, when examined under isotropic conditions (on plastic dishes), the cells migrated in all directions with the same probability (Fig. 1A; Table I). The analysis of cell trajectory also revealed a statistically significant difference in the average speed of movement, the displacement and the CME between prostate cancer cells moving on underlying fibroblasts and on the isotropic surface of culture dishes (Table I). As a result of both contact guidance and an increase in the speed of movement, the average displacement of DU-145 cells moving on fibroblasts was over 7 times greater than the displacement observed under control conditions on plastic substrata.

Characterization of the migration of DU-145 human prostate cancer cells on a grooved surface. To verify the hypothesis that the observed contact guidance of prostate cancer cells migrating on the surface of fibroblasts was the result of their reaction to the microtopography of the normal cells, in further experiments we studied the response of DU-145 cells to multiple grooved substrata of a size corresponding to the dimension of the compact monolayer culture of human skin fibroblasts. The analysis of fibroblast imaging by atomic force microscopy permitted an estimation of the dimensions of the anisotropic structures formed by normal cells in culture (Fig. 2). The dimensions of the structure were apparently irregular, but analysis of the average width of the grooves and ridges formed by fibroblasts in the monolayer culture and the depth 
Table I. Parameters characterizing the movement of DU-145 human prostate cancer cells moving on the surface of polystyrene, underlying fibroblasts or grooves.

Movement of DU-145 cells

Parameters

\begin{tabular}{ccc}
\hline Polystyrene $(\mathrm{n}=50)$ & Fibroblasts $(\mathrm{n}=100)$ & Grooves $(\mathrm{n}=100)$ \\
$132.8 \pm 6.4$ & $227 \pm 5.2^{\mathrm{a}}$ & $350.6 \pm 5.5^{\mathrm{ab}}$ \\
$16.6 \pm 0.8$ & $28.4 \pm 0.6^{\mathrm{a}}$ & $43.8 \pm 0.7^{\mathrm{ab}}$ \\
$13.6 \pm 1.5$ & $101.7 \pm 4.7^{\mathrm{a}}$ & $60.1 \pm 3.6^{\mathrm{ab}}$ \\
$1.7 \pm 0.2$ & $12.7 \pm 0.6^{\mathrm{a}}$ & $7.5 \pm 0.4^{\mathrm{ab}}$ \\
$0.11 \pm 0.01$ & $0.4 \pm 0.02^{\mathrm{a}}$ & $0.17 \pm 0.01^{\mathrm{ab}}$ \\
$0.02 \pm 0.01$ & $0.76 \pm 0.007^{\mathrm{a}}$ & $0.76 \pm 0.01^{\mathrm{a}}$ \\
$-0.1 \pm 0.01$ & $0.82 \pm 0.03^{\mathrm{a}}$ & $0.82 \pm 0.035^{\mathrm{a}}$ \\
0.5 & $8.98 \times 10^{-22}$ & $2.39 \times 10^{-29}$
\end{tabular}

Values are the means \pm SEM. aStatistically significant (DU-145 on polystyrene versus DU-145 on fibroblasts/grooves) at $\mathrm{P}<0.001$. ${ }^{\mathrm{b}} \mathrm{Statistically}$ significant (DU-145 on fibroblasts versus DU145 on grooves) at $\mathrm{P}<0.001$.
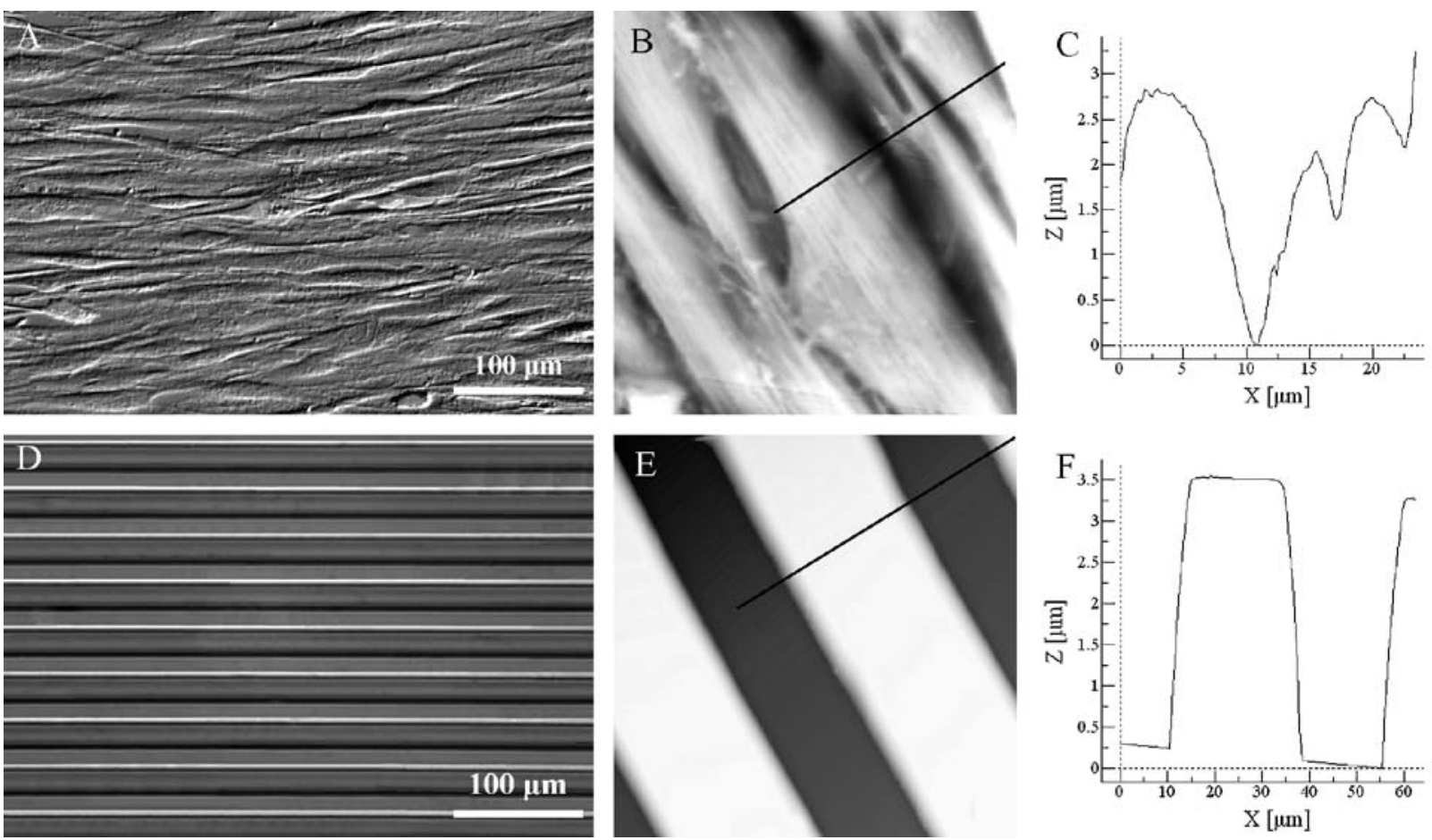

Figure 2. Characterization of topography of aligned human fibroblasts (A-C) and multiple grooved substrata (D-F). (A) Contact-inhibited human skin fibroblasts (Nomarski differential interference contrast); (B,C) analysis of fibroblast topography by atomic force microscopy; (D) microscopic image of patterned substrata with microfabricated grooves and ridges; (E,F) analysis of topography of patterned substrata by atomic force microscopy. Black lines in B and E represent the region of the cross-sections of measured surfaces shown in $\mathrm{C}$ and $\mathrm{F}$.

of the grooves allowed for an estimation of the dimensions of artificial multiple grooved substrata that imitated the natural topography of normal fibroblasts (Fig. 2). As a result of this analysis, we prepared a patterned substrata with microfabricated grooves $15 \mu \mathrm{m}$ wide and $3.5 \mu \mathrm{m}$ deep, and with $20-\mu \mathrm{m}$ wide ridges.

DU-145 cells grown on patterned substrata migrated along groove/ridge edges, indicated both by the shape of their trajectories orientated along the $0 \mathrm{X}$ axis (the axis parallel to the grooves) (Fig. 1C) and by the high value of the direction parameter (the average directional cosine) (Table I). Total cell translocation was over 4 times higher than on plain substrata. Generally, human prostate cancer cells moved faster and covered a longer distance than cells on plain substrata; however, the average final translocation was significantly lower than that of cells moving on the surface of fibroblasts $(\mathrm{P}<0.001)$. This effect was caused by the tendency of DU-145 cells on patterned substrata to move back and forth along the grooves, while cells moving on fibroblasts showed this pattern of migration less frequently. However, these results strongly 


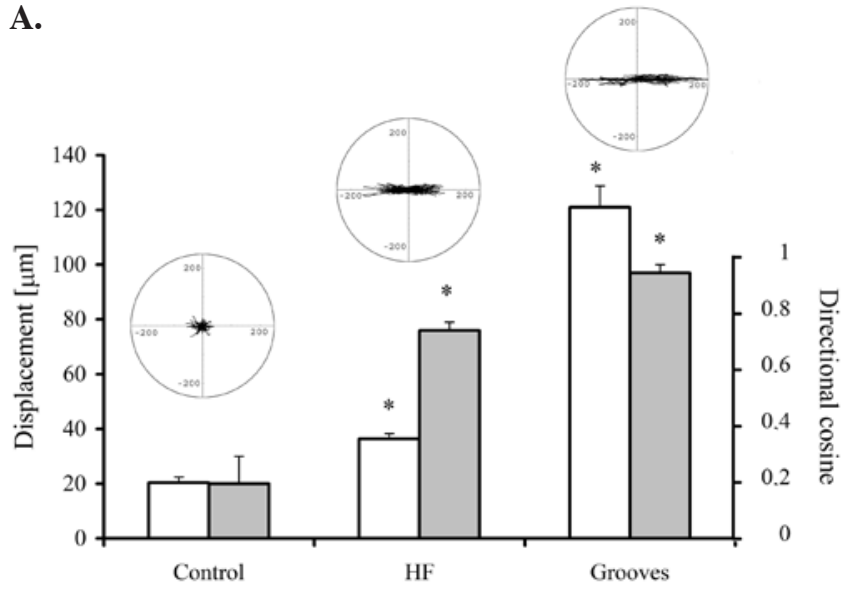

B.

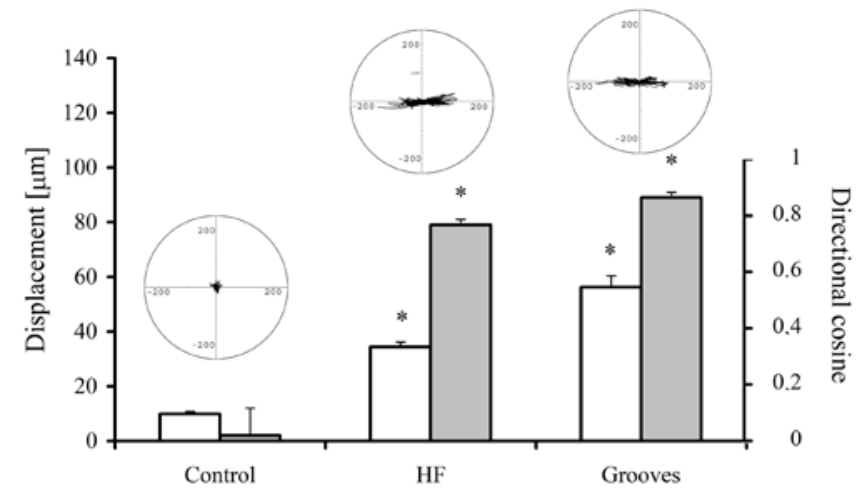

Figure 3. Summary of quantitative data showing the effect of the topography of fibroblasts and patterned substrata on the locomotion of (A) highly metastatic MAT-LyLu and (B) low metastatic AT-2 cells. The average cell translocation (open bars) and average directional cosine for final position (closed bars) were calculated for 50-100 cells. Error bars represent the SEM. "Statistically significant difference $(\mathrm{P}<0.001)$. Composite trajectories of migrating cells are displayed in circular diagrams in which the initial point of each trajectory is placed at the origin of the plot. Each trajectory was constructed from 48 successive positions of the cell centroid recorded over $8 \mathrm{~h}$ at 5 -min intervals. Scale bars: $\mu \mathrm{m}$.

suggest that human prostate cancer cells can be efficiently contact guided by the topography of the substratum.

The effect of microtopography on the migration of rat prostate cancer cells having markedly different metastatic abilities. In order to investigate whether the observed reaction to microtopography was correlated with the metastatic activity of prostate cancer cells, in subsequent experiments we compared the migration of highly metastatic MAT-LyLu and low metastatic AT-2 rat prostate cancer cells, which have markedly different metastatic abilities. Prostate cancer cells of both lines migrated on the dorsal surface of fibroblasts primarily along the long axis of the underling fibroblasts, and analysis of their trajectories revealed a statistically significant increase in directionality of movement (Fig. 3). As a result of contact guidance, the average displacement of MAT-LyLu and AT-2 cells moving on fibroblasts was, respectively, 2 and 3 times greater than the displacement observed under control conditions. However, no significant difference was observed between the motile activity of the AT-2 and MAT-LyLu cells migrating on the surface of normal cells.
Both investigated cell lines grown on patterned substrata migrated along groove/ridge edges, indicated by the shapes of their trajectories orientated along the $0 \mathrm{X}$ axis and by the high value of the direction parameter (the average directional cosine) (Fig. 3). As a result of directional movement, the average cell displacement of MAT-LyLu and AT-2 cells during the 4-h experiment was $121 \pm 8 \mu \mathrm{m}$ and $56 \pm 4 \mu \mathrm{m}$, respectively. Interestingly, both cell lines showed more efficient contact guidance on artificial substrata than on the surface of normal cells. Moreover, the results demonstrated that highly metastatic MAT-LyLu were more efficiently contact guided by the topography of substratum than low metastatic AT-2 cells.

\section{Discussion}

In the present study, we demonstrated that the migration of prostate cancer cells may be efficiently affected by topographical features of the substratum. In contrast to random movement under control conditions, all the investigated prostate cancer cell lines grown on patterned substrata migrated mainly along artificial grooves and covered, as a result of contact guidance, a longer distance than cells on plain substrata. Moreover, our results demonstrate that the reaction to microtopography was correlated with the metastatic activity of prostate cancer cells. It has been demonstrated in several reports that tumour cells can efficiently respond to numerous factors affecting their motility, including chemotactic peptides, extracellular matrix components, electric fields and cell-to-cell contact $(3,4,6,13,14)$. However, the role of substrata topography in the regulation of cancer cell motility has been quantitatively studied in only a few reports (23). For the most part, the contact guidance of cancer cells has been estimated by the orientation and morphology of the investigated cells $(20-22,24)$, and the general conclusion of these studies is that cancer cells do not react efficiently to the topography of the substratum.

On the other hand, several reports have suggested that tissue architecture is likely to be an important determinant of cancer cell migration. Abercrombie (8) suggested that not only the defective contact inhibition of the movement of malignant cells contributes to their invasiveness, but also that some tumour cells may be contact guided by underlying normal cells during invasion and, as a result, show fast and effective cell displacement. The effect of tissue architecture on the invasion of tumour cells has also been observed in several cases in vivo (31-33). For instance, neurotropic melanoma of the head and neck demonstrate the characteristic perineural invasion of and extension along cranial nerves to the central nervous system (32).

In the present report, we demonstrate that, as a result of the polarization of cell migration (contact guidance) and an increase in speed of movement, DU-145 human prostate cancer cells moving on the surface of fibroblasts showed significantly greater cell displacement than control cells moving on isotropic plastic substrata. These results indicate that the direct contact of prostate cancer cells with normal cells may facilitate their migration during invasion. A similar observation was previously reported for other tumour cells $(9,11,12,15)$, including rat prostate cancer cell lines (16). In a previous study (15), we suggested that the alignment and anisotropic distribution of fibronectin macromolecules on the surface of normal cells 
may be at least in part responsible for the contact guidance of Walker carcinosarcoma cells moving on fibroblasts. However, another possibility is that the contact guidance of cancer cells resulted from their reaction to the topography of the tissue determined by the orientation of normal cells. Indeed, here we demonstrated that DU-145 cells were efficiently contact guided when grown on multiple grooved substrata of a size corresponding to the dimensions of the compact monolayer culture of human skin fibroblasts. These observations strongly suggest that the anisotropy of substratum resulting from normal cell arrangement is sufficient for the induction of contact guidance and directional movement in prostate cancer cells.

A similar reaction was observed in the case of the migration of MAT-LyLu and AT-2 cells, rat prostate cancer cells with markedly different metastatic abilities. Interestingly, highly metastatic MAT-LyLu cells were very sensitive to topography. The average displacement of MAT-LyLu cells moving on patterned substrata was $121 \pm 8 \mu \mathrm{m}$ (6 times greater than the displacement observed under control conditions on plain substrata and 2 times greater than the displacement of low metastatic AT-2 cells). Our results reveal that prostate cancer cells are not only efficiently contact guided by topography, but also suggest that this reaction is correlated with the metastatic activity of cancer cells. A correlation between reaction to topography and the metastatic activity of cancer cells was also suggested by Condeelis and Segall (34). In elegant studies using intravital imaging of cell movement in tumours in vivo, these authors demonstrated that, in contrast to non-metastatic rat mammary MTC cells, highly metastatic MTLn3 cells were efficiently contact guided by collagen-containing fibers. As a result of this reaction, MTLn3 cells showed linear, fiber-associated locomotion leading to effective and fast cell translocation.

In summary, our results clearly demonstrate that grooved substrata have a substantial effect on prostate cancer migration. Since all types of tissue show some kind of patterning and alignment, topographic factors may be crucial for the effective migration of prostate cancer cells during the metastatic process.

\section{Acknowledgments}

We thank Professor W. Korohoda and Professor M. Szymonski for continuous support and helpful discussions. This work was supported by grants N N301 286637 and N N302 061936 from the Polish Ministry of Science and Higher Education.

\section{References}

1. Grimstad IA: Direct evidence that cancer cell locomotion contributes importantly to invasion. Exp Cell Res 173: 515-523, 1987.

2. Stracke ML, Aznavoorian SA, Beckner ME, Liotta LA and Schiffmann E: Cell motility, a principal requirement for metastasis. In: Cell Motility Factors. Goldberg ID (ed). Birkhauser Verlag, Basel, pp147-162, 1991.

3. Aznavoorian S, Stracke ML, Krutzsch H, Schiffmann E and Liotta LA: Signal transduction for chemotaxis and haptotaxis by matrix molecules in tumor cells. J Cell Biol 110: 1427-1438, 1990.

4. Levine MD, Liotta LA and Stracke ML: Stimulation and regulation of tumor cell motility in invasion and metastasis. EXS 74: 157-179, 1995.
5. Reuning U, Magdolen V, Wilhelm O, Fischer K, Lutz V, Graeff H and Schmitt M: Multifunctional potential of the plasminogen activation system in tumor invasion and metastasis. Int $\mathbf{J}$ Oncol 13: 893-906, 1998.

6. Djamgoz MBA, Mycielska M, Madeja Z, Fraser SP and Korohoda W: Directional movement of rat prostate cancer cells in electric field: control by voltage-gated $\mathrm{Na}^{+}$channel activity. J Cell Sci 114: 2697-2705, 2001.

7. Abercrombie $\mathrm{M}$ and Turner AA: Contact reactions influencing cell locomotion of a mouse sarcoma cells in culture. Med Biol 56: 299-303, 1978.

8. Abercrombie M: Contact inhibition and malignancy. Nature 281: 259-262, 1979.

9. Paddock SW and Dunn GA: Analysing collisions between fibroblasts and fibrosarcoma cells: Fibrosarcoma cells show an active invasionary response. J Cell Sci 81: 163-187, 1986.

10. Gail MH and Boone CW: Density inhibition of motility in 3T3 fibroblasts and their SV40 transformants. Exp Cell Res 64: 156-162, 1971.

11. Thomas LA and Yamada KM: Contact stimulation of cell migration. J Cell Sci 103: 1211-1214, 1992.

12. Korohoda W and Madeja Z: Contact of sarcoma cells with aligned fibroblasts accelerates their displacement: computer-assisted analysis of tumour cell locomotion in co-culture. Biochem Cell Biol 75: 263-276, 1997.

13. Madeja Z, Miekus K, Sroka J, Djamgoz MBA and Korohoda W: Homotypic cell-cell contacts stimulate the motile activity of rat prostate cancer cells. BJU Int 88: 776-786, 2001.

14. Madeja Z, Szymkiewicz I, Zaczek A, Sroka J, Miekus K and Korohoda W: Contact-activated migration of melanoma B16 and sarcoma XC cells. Biochem Cell Biol 79: 425-440, 2001.

15. Madeja $Z$ and Sroka J: Contact guidance of Walker carcinosarcoma cells by the underlying normal fibroblasts is inhibited by RGD-containing synthetic peptides. Folia Histochem Cytobiol 40: 251-260, 2002.

16. Miekus K, Czernik M, Sroka J, Czyz J and Madeja Z: Contact stimulation of prostate cancer cell migration: The role of gap junctional coupling and migration stimulated by heterotypic cell-to-cell contacts in determination of metastatic phenotype of Dunning rat prostate cancer cells. Biol Cell 97: 893-903, 2005.

17. Easty GC and Easty DM: An organ culture system for the examination of tumour invasion. Nature 199: 1104-1105, 1963.

18. Leighton J, Kalla RL, Kline I and Belkin M: Pathogenesis of tumor invasion. I. Interaction between normal tissues and transformed cells in tissue culture. Cancer Res 19: 23-27, 1959.

19. Curtis A and Wilkinson C: Topographical control of cells. Biomaterials 18: 1573-1583, 1997.

20. Fisher PE and Tickle C: Differences in alignment of normal and transformed cells on glass fibres. Exp Cell Res 131: 407-410, 1981.

21. McCartney MD and Buck RC: Comparison of the degree of contact guidance between tumor cells and normal cells in vitro. Cancer Res 41: 3046-3051, 1981.

22. Rovensky YuA and Samoilov VI: Morphogenetic response of cultured normal and transformed fibroblasts, and epitheliocytes, to a cylindrical substratum surface. Possible role for the actin filament bundle pattern. J Cell Sci 107: 1255-1263, 1994.

23. Mello AP, Volkov Y, Kelleher D and Prendergast PJ: Comparative locomotory behavior of $\mathrm{T}$ lymphocytes versus T lymphoma cells on flat and grooved surfaces. Ann Biomed Eng 31: 1106-1113, 2003.

24. Dalby MJ, Hart A and Yarwood SJ: The effect of the RACK1 signalling protein on the regulation of cell adhesion and cell contact guidance on nanometric grooves. Biomaterials 29: 282-289, 2008.

25. Wojciak-Stothard B, Madeja Z, Korohoda W, Curtis A and Wilkinson C: Activation of macrophage-like cells by multiple grooved substrata. Topographical control of cell behaviour. Cell Biol Int 19: 485-490, 1995.

26. Isaacs JT, Isaacs WB, Feitz WFG and Scheres J: Establishment and characterization of seven Dunning rat prostatic cancer cell lines and their use in developing methods for predicting meta-stating abilities of prostatic cancers. Prostate 9: 261-281, 1986.

27. Charest J, Bryant L, Garcia A and King W: Hot embossing for micropatterned cell substrates. Biomaterials 25: 4767-4775, 2004.

28. Chou S, Krauss P and Ronstrom P: Imprint lithography with 25-nanometer resolution. Science 272: 85-87, 1996. 
29. Daniel-Wójcik A, Misztal K, Bechyne I, Sroka J, Miekus K, Madeja Z and Czyz J: Cell motility affects the intensity of gap junctional coupling in prostate carcinoma and melanoma cell populations. Int J Oncol 33: 309-315, 2008.

30. Sroka J, Antosik A, Czyz J, Nalvarte I, Olsson JM, Spyrou G and Madeja Z: Overexpression of thioredoxin reductase 1 inhibits migration of HEK-293 cells. Biol Cell 12: 677-687, 2007.

31. Burger PC, Heinz ER, Shibata T and Kleihues P: Topographic anatomy and CT correlations in the untreated glioblastoma multiforme. J Neurosurg 68: 698-704, 1988.
32. Gentile RD and Donovan DT: Neurotropic melanoma of the head and neck. Laryngoscope 95: 1161-1166, 1985.

33. Mack EE and Gomez EC: Neurotropic melanoma. A case report and review of the literature. J Neurooncol 13: 165-171, 1992.

34. Condeelis J and Segall JE: Intravital imaging of cell movement in tumours. Nat Rev Cancer 3: 921-930, 2003. 
